\title{
On particles in the Arctic stratosphere
}

\author{
Torben S. Jørgensen \\ Danish Meteorological Institute, Copenhagen, Denmark
}

\begin{abstract}
Soon after the discovery of the Antarctic ozone hole it became clear that particles in the polar stratosphere had an influence on the destruction of the ozone layer. Two major types of particles, sulphate aerosols and Polar Stratospheric Clouds (PSCs), provide the surfaces where fast heterogeneous chemical reactions convert inactive halogen reservoir species into potentially ozone-destroying radicals. Lidar measurements have been used to classify the PSCs. Following the Mt. Pinatubo eruption in June 1991 it was found that the Arctic stratosphere was loaded with aerosols, and that aerosols observed with lidar and ozone observed with ozone sondes displayed a layered structure, and that the aerosol and ozone contents in the layers frequently appeared to be negatively correlated. The layered structure was probably due to modulation induced by the dynamics at the edge of the polar vortex. Lidar observations of the Mt. Pinatubo aerosols were in several cases accompanied by balloon-borne backscatter soundings, whereby backscatter measurements in three different wavelengths made it possible to obtain information about the particle sizes. An investigation of the influence of synoptic temperature histories on the physical properties of PSC particles has shown that most of the liquid type $1 b$ particles were observed in the process of an ongoing, relatively fast, and continuous cooling from temperatures clearly above the nitric acid trihydrate condensation temperature $\left(T_{\mathrm{NAT}}\right)$. On the other hand, it appeared that a relatively long period, with a duration of at least 1-2 days, at temperatures below $T_{\mathrm{NAT}}$ provide the conditions which may lead to the production of solid type 1a PSCs.
\end{abstract}

Key words Arctic stratosphere-ozone layer-polar stratospheric clouds - sulphate aerosols

\section{Introduction}

The occurrence of particles in the stratosphere has been known for more than a century. Stanford and Davis (1974) presented results from a careful and systematic search for reports of Polar Stratospheric Clouds (PSCs) over the period 1870-1972 and found for the high-latitude Northern Hemisphere a total of 156 dates on which so-called mother-of-pearl clouds were reported. Considering the sparsity of Antarctic observers in this period it appears that stratospheric clouds

Mailing address: Dr. Torben S. Jørgensen, Danish Meteorological Institute, Lyngbyvej 100, DK-2100 Copenhagen, Denmark; e-mail: torben.s.j@mail.tele.dk occur much more frequently in the high-latitude Southern Hemisphere than in the corresponding region of the Northern Hemisphere. This is of course now known to be a result of the much colder Antarctic stratosphere.

A peculiar fact about the cloud observations compiled by Stanford and Davis (1974) is that whereas clouds were observed regularly and most of the years during the periods 1870-1895 and 1926-1972, observations of stratospheric clouds from 1896 to 1925 were not reported. The reason for the lack of clouds in this period is not known, but it does not seem to result from lack of observations. Thus the very competent and diligent Norwegian observer Størmer for example reported: «after 1892 I did not see them at all in spite of a very careful watch. It was not until December 27, 1926, that I saw them again» (Størmer, 1929). A reason for the 30 year long period without observations of stratospheric clouds might be that the stratospheric temperature was too high for PSCs to be formed due to 
the unusual high volcanic activity at that time. Thus Krakatau (1883), Santa Maria (1902) and Novarupta also known as Katmai (1912) are listed with the highest volcanic explosivity indices since Tambora (1815) (Briffa et al., 1998).

Stanford and Davis (1974) reported only published observations of stratospheric clouds and found as mentioned no events between 1895 and 1926. They did not know that a Danish painter, Harald Moltke, in the winter 1900-1901 participated in an expedition to Utsjoki in Northern Finland with the purpose of studying the aurora, and that he accidentally one day saw and painted a PSC. Moltke's job was to produce pictures of the aurora, since colour film was not yet invented. He should not make artist's impressions but observations. He made several paintings in oil, and on the backside of each canvas he wrote date and time in hours and minutes of the event. Some of these paintings are reproduced in books (e.g., Eather, 1980).

At the Danish Meteorological Institute, where all Moltke's auroral paintings are kept, a few years ago we were wondering why one of the paintings did not show any aurora but just a rather boring landscape with the sun a few degrees below the horizon. Suddenly it became obvious that the painting was made because of a cloud appearing in the upper left corner, and that this cloud was a PSC. Date, year, and time was January 5, 1901, at 1215 p.m. (fig. 1). It is not known if the participants in the auroral expedition a hundred years ago had any knowledge about clouds in the stratosphere, but they found the cloud that day interesting enough to document in very likely the first picture of a PSC ever made.

Sidney Chapman, who often had the right notions about processes in the Earth's atmosphere once wrote: «The physical implications of the presence of these clouds at their considerable height in the stratosphere are, and for some time may remain, obscure; but possibly they will play a significant part, along with such other remarkable facts as those of the ozone relations ...» (Chapman, 1932). However, it was not until more than half a century later, after the discovery of the Antarctic ozone hole (Farman et al., 1985) that it became clear that particles in the polar stratosphere have an important role

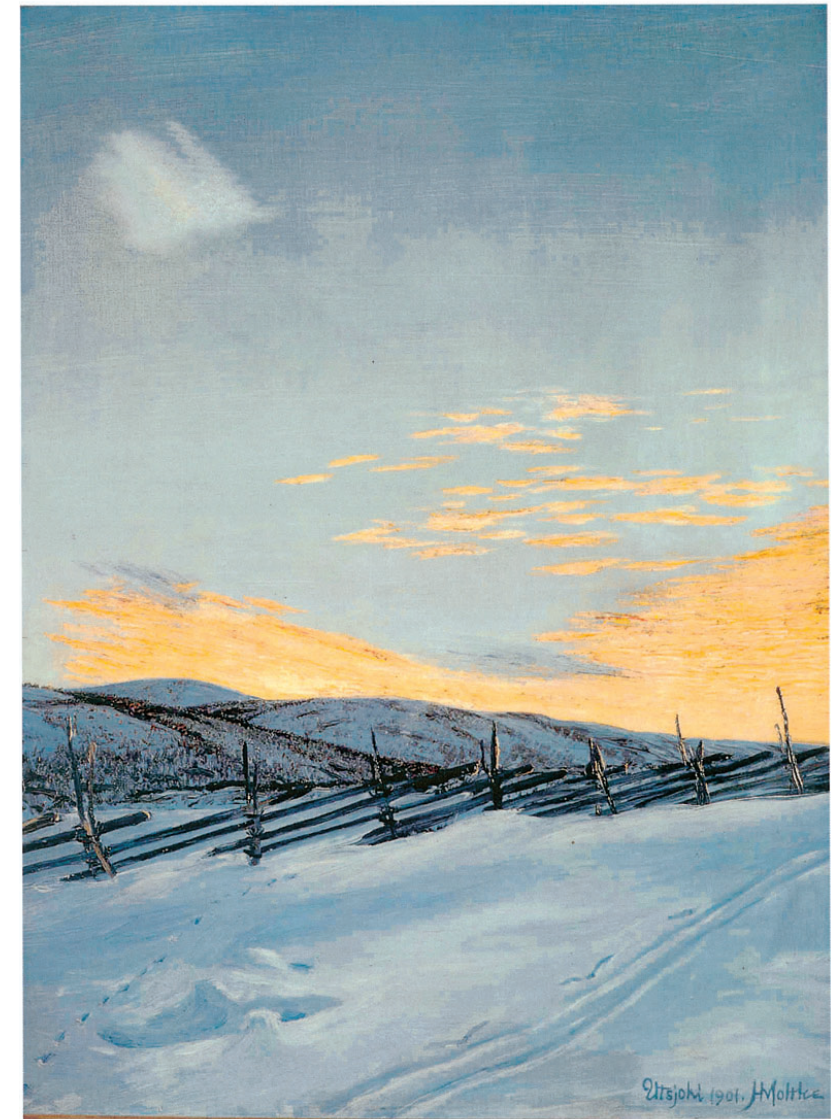

Fig. 1. Polar stratospheric cloud, January 5, 1901, 1215 p.m., Utsjoki, Finland. Oil painting by Harald Moltke.

in the process that results in destruction of the ozone layer (Solomon, 1986).

Two major types of particles are observed in the lower stratosphere, namely the sulphate aerosol and PSCs. The stratospheric aerosol and cloud particles provide the surfaces where fast heterogeneous chemical reactions convert inactive halogen reservoir species into potentially ozone-destroying radicals. The stratospheric sulphate aerosol layer consists of sub-micron sized liquid particles, composed of sulfuric acid and water (Turco et al., 1982). The particles are found globally between the tropopause and up to an altitude of about $30 \mathrm{~km}$. For a few years following major explosive volcanic eruptions the abundance of sulphate aerosol particles may increase dramatically, as it happened after the eruptions of El Chicon in 1982 and Mt. Pinatubo in 1991 (fig. 2). Explosive volcanic 

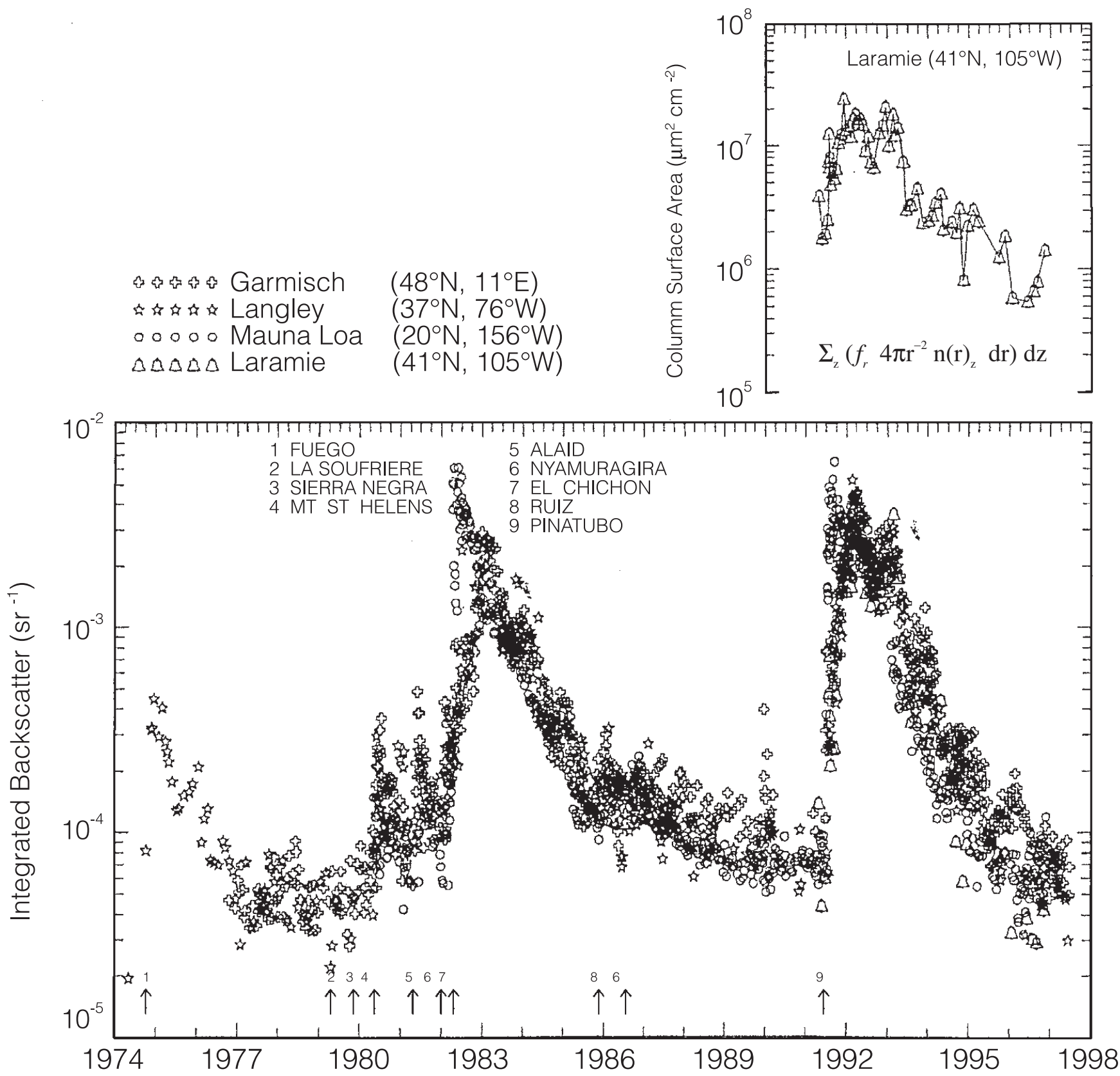

Fig. 2. Time variation of the stratospheric aerosol layer at Northern Hemisphere midlatitudes. The plot shows the integrated aerosol backscatter at a wavelength of $0.6943 \mu \mathrm{m}$ from lidar measurements at Garmisch-Partenkirchen, NASA Langley, and Mauna Loa for the period 1974-1998. Also shown for the period 1991-1997 is integrated aerosol backscatter calculated from size distributions fitted to in situ data above Laramie. The calculations assume particles with an index of refraction of 1.45. Also shown are column integrals of surface area from the 1991-1997 in situ data. The column integrals are from the tropopause to near $33 \mathrm{~km}$ for all the data. Arrows indicate prominent volcanic eruptions (World Meteorological Organization, 1999).

eruptions are the major source of sulphur in the stratosphere. Gaseous sulfuric acid in the stratosphere is generated from the oxidation of predominantly carbonyl sulphide resulting from biological processes and biomass and fossil fuel burning (Weiss et al., 1995) and sulphur dioxide injected directly into the stratosphere by volcanic eruptions. 
The PSCs are composed of nitric acid and water. Gravitational sedimentation of the particles may lead to a vertical redistribution of these species with irreversible denitrification and dehydration in the altitude range where the particles form, prolonging chemical ozone destruction by reactive chlorine. The Arctic interannual temperature variability will also introduce a large variability in PSC properties. Only occasionally has denitrification been observed in the Arctic stratosphere in contrast to Antarctica where a nearly complete and regular denitrification takes place each year in the lower stratosphere inside the polar vortex.

\section{Observations}

Stratospheric particles are observed by a variety of measurement techniques. Instruments to measure the stratospheric sulfate aerosol can be broadly divided into two categories, those that provide ensemble measurements and those that provide individual particle measurements. Ensemble measurements detect the signature of a population of particles at one instant and include active scattering measurements, such as lidar (Fiocco and Grams, 1964).

Satellite measurements have provided a climatology of the stratospheric aerosol (Hitchman et al., 1994). Measurements by SAGE II (Trepte et al., 1993) allowed the evolution and dispersion of the Pinatubo volcanic aerosol plume to be studies on a global scale. Lidar backscatter and depolarisation measurements have been used to to classify the PSCs: two types of PSCs forming respectively above (type 1) and below (type 2$)$ the ice frost point temperature $\left(T_{\text {ice }}\right)$ were originally identified. The former type was later subdivided into lidar depolarising (presumably solid) type 1a PSCs and non-depolarising (liquid) type 1 b PSCs (fig. 3). Whereas type 2 PSCs are composed of water ice particles, it was originally suggested that type 1 PSCs were composed of Nitric Acid Trihydrate (NAT) which is stable at the stratospheric conditions. However, some type 1 PSCs were observed in the Arctic at high supersaturations with respect to NAT. Airborne particle volume measurements later showed an excellent agreement with models, assuming the
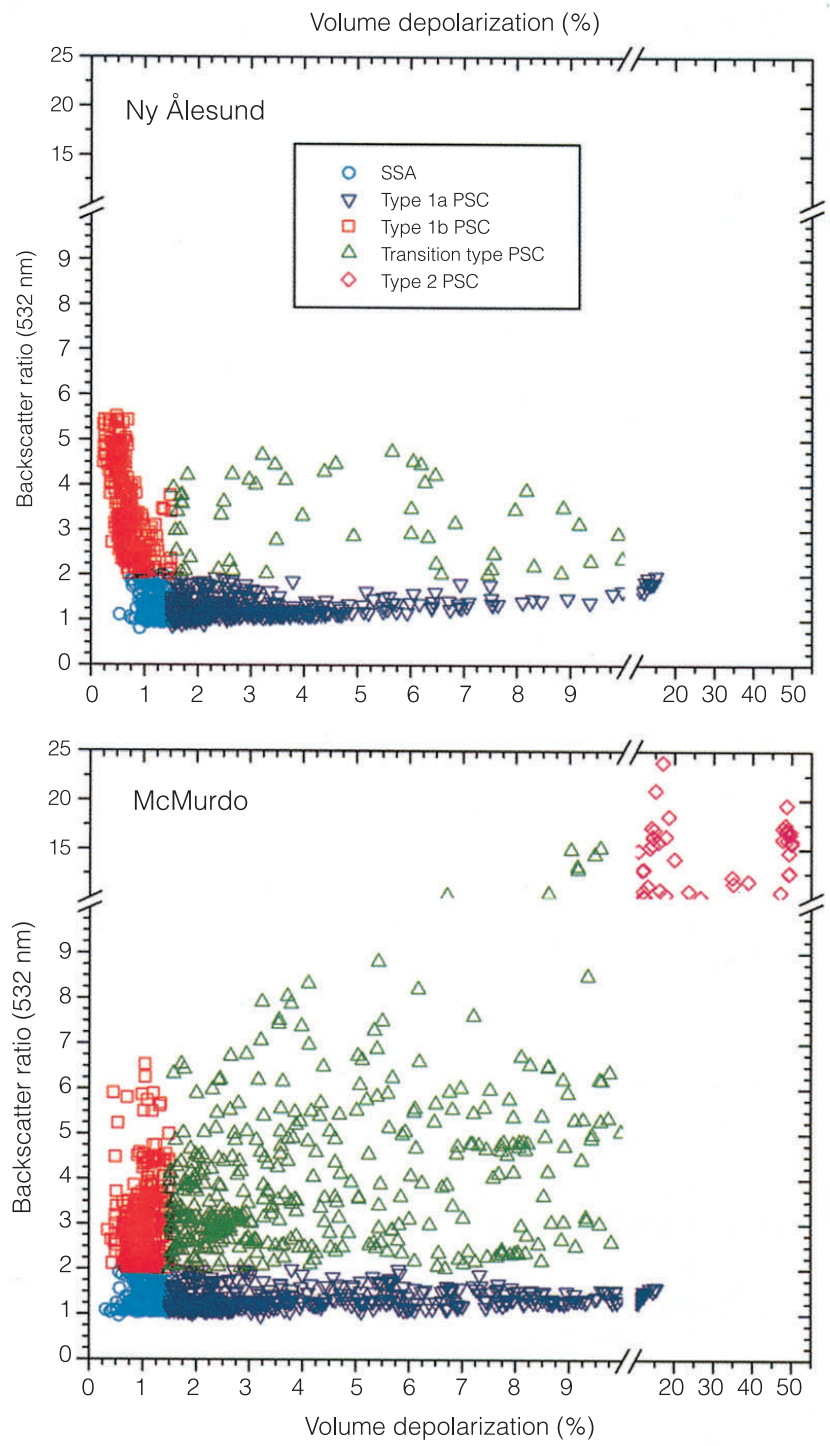

Fig. 3. Scatter plot of $532 \mathrm{~nm}$ backscatter ratio versus volume depolarisation from lidar measurements at $\mathrm{Ny}$ Ålesund, Spitsbergen (upper panel) and Antarctic measurements at McMurdo (lower panel), illustrating the grouping of different particle types observed in the polar winter stratosphere (adapted from World Meteorological Organization, 1999, courtesy R. Neuber and A. Adriani).

particles to be composed of liquid Supercooled Ternary Solutions (STS; $\mathrm{HNO}_{3} / \mathrm{H}_{2} \mathrm{SO}_{4} / \mathrm{H}_{2} \mathrm{O}$ ) (Carslaw et al., 1994; Tabazadeh et al., 1994). Various lidar observations and airborne and balloon-borne measurements are consistent with the description of type 1b PSCs as composed of STS particles. The composition and, in particular, the formation of solid type PSCs and their 
Northern Hemisphere implications are much more uncertain. Airborne lidar measurements in mountain waves over Northern Scandinavia have provided short-term quasi-Lagrangian pictures of PSC formation and evolution (e.g., Carslaw et al., 1998). Basically, these measurements are made by flying parallel to the wind at the level of the cloud under mountain wave-induced PSCs that are assumed to be stationary. Such measurements of particles in mountain wave clouds have shown that essentially all liquid particles freeze directly into ice when the air is cooled adiabatically to temperatures at least 3-4 $\mathrm{K}$ below $T_{\text {icce }}$.

In situ balloon-borne experiments have measured the chemical composition of PSC particles for the first time. Particle compositions from the first flight in 1998, downwind of the Scandinavian mountains, are consistent with STS droplets (Schreiner et al., 1999; Larsen et al., 2000). More comprehensive analysis of two later flights identified for the first time PSC particles composed of NAT at temperatures up to or even slightly above $T_{\mathrm{NAT}}$, with layers of STS particles at much lower temperatures close to $T_{\text {ice }}$ (Voigt et al., 2000). These flights showed a clear correspondance between chemical composition, size distributions, and optical properties of the particles.

Direct measurements of particle size distributions have been obtained from balloon-borne optical counters and airborne particle spectrometers and impactors.

As indicated lidars are important instruments for investigation of particles in the stratosphere. This was also realized in 1991, when the Network for Detection of Stratospheric Change (NDSC) was established, and aerosol lidars were recommended as standard instruments at all NDSC primary stations, and they were quickly installed at the four Arctic sites Eureka in Canada, Ny Ålesund at Svalbard, and Thule and Søndre Strømfjord both in Greenland. Lidars are also installed at the NDSC complementary sites at Andøya in Norway, Kiruna in Sweden, and Sodankylä in Finland. In the following some of the Arctic lidar observations will be discussed.

Aerosol backscattering profiles were measured at Thule with the University of Rome lidar, which is equipped with a $0.8 \mathrm{~m}$ diameter telescope and a neodymium: Yttrium/Aluminum/
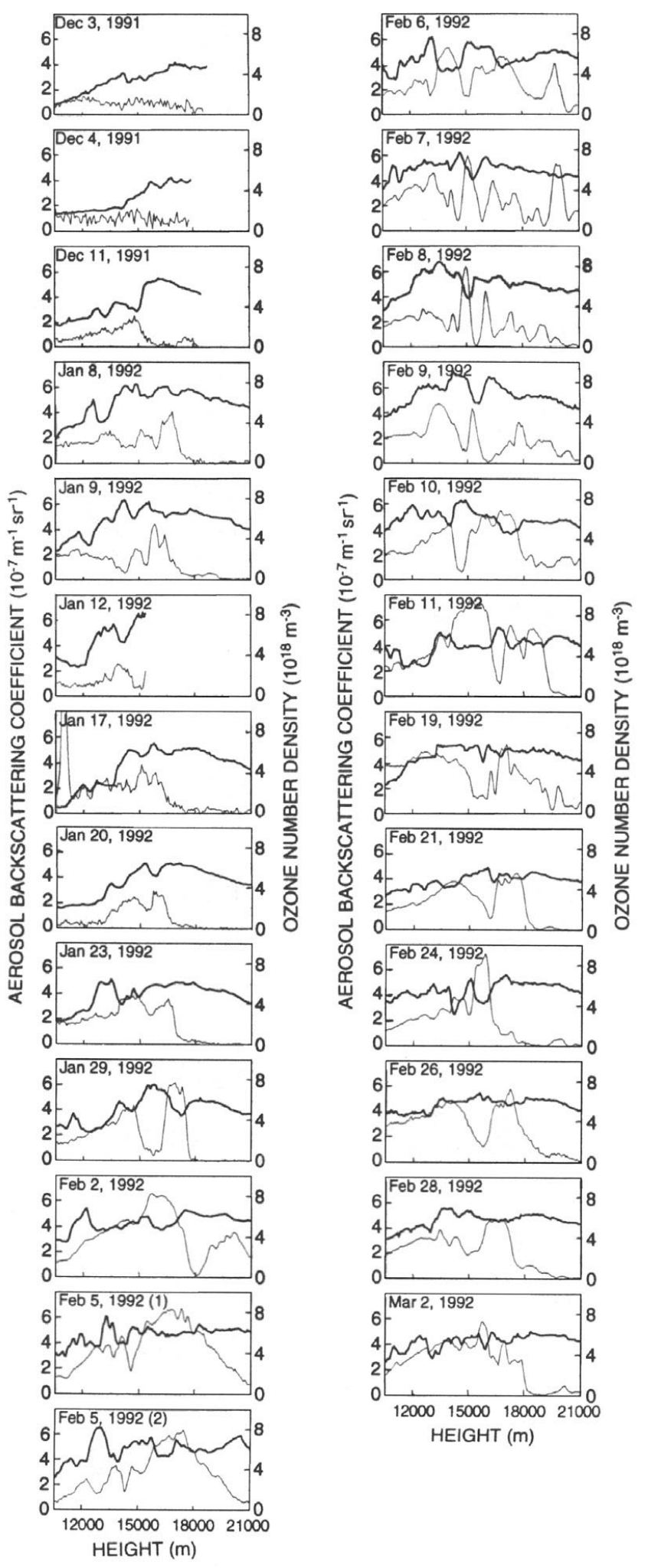

Fig. 4. Sequence of vertical profiles of aerosol backscattering (thin line) and ozone number density (heavy line), observed with lidar at Thule from December 3, 1991 to March 2, 1992 (di Sarra et al., 1992). 
Garnet (Nd:YAG) laser emitting pulses of approximately $100 \mathrm{~mJ}$ at $532 \mathrm{~nm}$. A more detailed description of the instrument and of the data analysis procedure is given by Di Girolamo et al. (1994). In the winter 1991-1992 intensive series of aerosol measurements were carried out. In the same period ECC ozone sondes were launched also from Thule by the Danish Meteorological Institute. It was found (di Sarra et al., 1992), that the Arctic stratosphere was loaded with aerosols originating from the Mt. Pinatubo eruption in June 1991, and that both the aerosol and the ozone profiles displayed a layered structure. The aerosol and ozone contents in the layers frequently appeared to be negatively correlated, particularly in the height region around $16 \mathrm{~km}$ (fig. 4). As in previous observations (e.g., Grams and Fiocco, 1967) the most straightforward interpretation of the anticorrelation between aerosols and ozone is to relate it to different properties of the air coming from different regions and the history of the air parcels. Layered structures in the ozone profile throughout the lower stratosphere are common at high latitudes; it has been suggested that transport processes could be responsible for such laminations (e.g., Reid and Vaughan, 1991). Throughout the period of observation, Thule was close to the edge of the vortex; it appears that air coming from inside the vortex was richer in ozone and poorer in aerosol than air coming from outside. Moreover, the trajectory analysis indicates that the air parcels reaching Thule at the same time at different height levels often come from different latitudes.

The relation between ozone and aerosol at Thule was also investigated in the two following winters 1992-1993 and 1993-1994 with corroborative results (di Sarra et al., 1995). The average correlation coefficient between the aerosol and ozone deviations as a function of height for the three winters is shown in fig. 5. The correlation coefficient is consistently negative in the three winters throughout the region 13 to 19 $\mathrm{km}$, and the negatively correlated region seems to progressively descend, probably following the aerosol displacement. The presence of the negatively correlated behavior between aerosol and ozone may be explained by the motion of air layers with different characteristics across

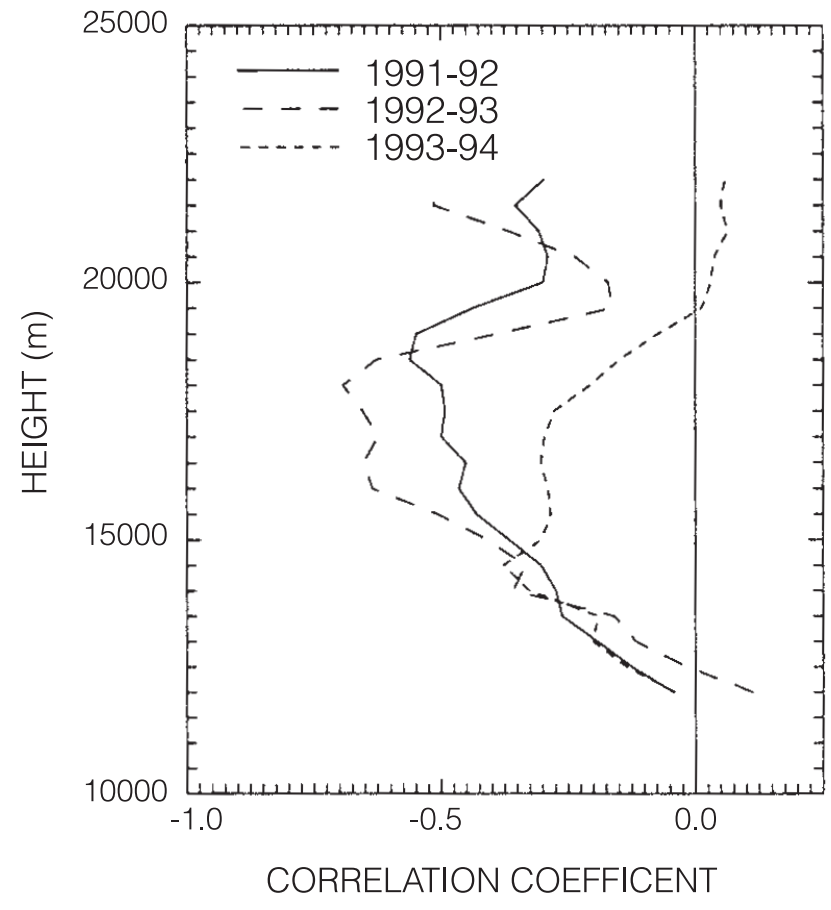

Fig. 5. Average correlation coefficient between the aerosol and ozone deviations as a function of height for the winters 1991-1992, 1992-1993 and 1993-1994 (di Sarra et al., 1995).

the vortex boundary, occurring mainly in the stratospheric region below $18 \mathrm{~km}$. The presence of this dynamically induced modulation masks possible ozone-aerosol interactions originated through chemical or radiative processes. However, although most of the negatively correlated behavior of ozone and aerosol may be explained through transport phenomena, evidence of chemical processing inside the vortex (enhanced $\mathrm{ClO}$ concentrations) at Thule during February and March 1993 have been reported (Shindell et al., 1994). The increase in $\mathrm{ClO}$ may be attributed to reactions taking place either on PSCs or on the aerosol surface. An increase of $\mathrm{ClO}$ and a reduction of ozone was observed by the UARS satellite in the same period (Manney et al., 1994), and Larsen et al. (1994a) calculated, using ozone soundings carried out in 1993 at Thule, that an ozone reduction of $1.9 \% /$ day occurred at $400 \mathrm{~K}$ during February and March in the Arctic.

Di Girolamo et al. (1994) detected the Pinatubo aerosols in the stratosphere at Thule from late September 1991, and observed that the aerosol 


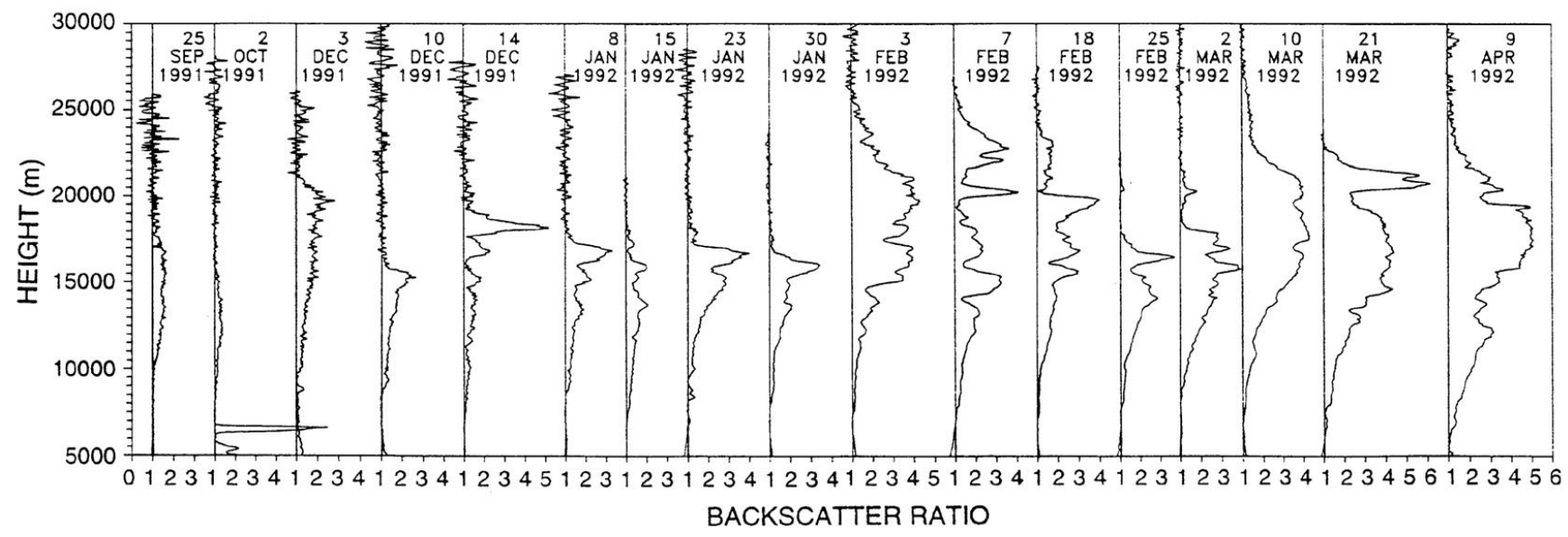

Fig. 6. Backscatter ratio profiles measured with lidar at Thule (Di Girolamo et al., 1994).

load slowly increased during autum and early winter. Above approximately $18 \mathrm{~km}$ 's altitude the aerosol load depended on the location of the station relative to the polar vortex. A temporary increase in the aerosol concentration was detected up to about $26 \mathrm{~km}$ at the beginning of February, when Thule was located for a few days outside the vortex (fig. 6). A final increase of the aerosol load was related with the final breakup of the vortex. There was no evidence of large PSC events during this winter over Thule consistent with the relatively high stratospheric temperatures in that period and in that region of the Arctic.

The time series of lidar backscatter ratio (defined as the ratio of the total backscatter intensity from both molecules and particles to the backscattered intensity from molecules alone) are shown in fig. 7 (Neuber et al., 1994). At midlatitudes the volcanic cloud was observed in early July 1991 less than a month after the eruption. The aerosol increase at high latitudes through meridional dispersion then proceeded and was completed about 10 months after the eruption (Chazette et al., 1995). At polar latitudes the volcanic particle distribution was clearly related to the polar vortex location. Volcanic aerosol were removed from the lower stratosphere through sedimentation followed by stratospheretroposphere exchange (Jäger et al., 1995).

Mt. Pinatubo aerosols were also observed during 6 balloon-borne backscatter soundings in January and February 1992 under different polar vortex conditions from Thule (Larsen et al., 1994b). It was found that the vortex boundary seemed to retard stratospheric aerosol mixing into the inner parts of the vortex from lower latitudes; however, when Thule was outside the vortex large aerosol loadings were measured. The backscatter sonde, developed by the University of Wyoming (Rosen and Kjome, 1991) was equipped with a xenon flashlamp, giving a collimated horizontal light pulse about once every $7 \mathrm{~s}$. The backscattered light from the aerosol was detected in two wavelengths bands around 480 $\mathrm{nm}$ (blue) and $940 \mathrm{~nm}$ (red). The payload also included an ECC ozone sonde and a temperature and pressure sensor. The vertical resolution was about $30 \mathrm{~m}$. The aerosols were simultaneously observed with the University of Rome lidar, whereby aerosol backscatter measurements in three different wavelengths made it possible to obtain information about the particle sizes. Parameters of lognormal distributions were derived, using a least square approach between observed and calculated backscatter coefficients from Mie theory. The aerosol surface area density was increased by factors 10-50, compared to the background levels at pre-volcanic conditions.

Two vertical profiles of backscatter ratios (i.e. the ratio between the particulate and molecular (Rayleigh) volume backscattering coefficients to the molecular backscattering) in the 3 wavelengths are shown in fig. 8a,b together with the observed ozone partial pressures. In the period covering the first four flights from January 12 

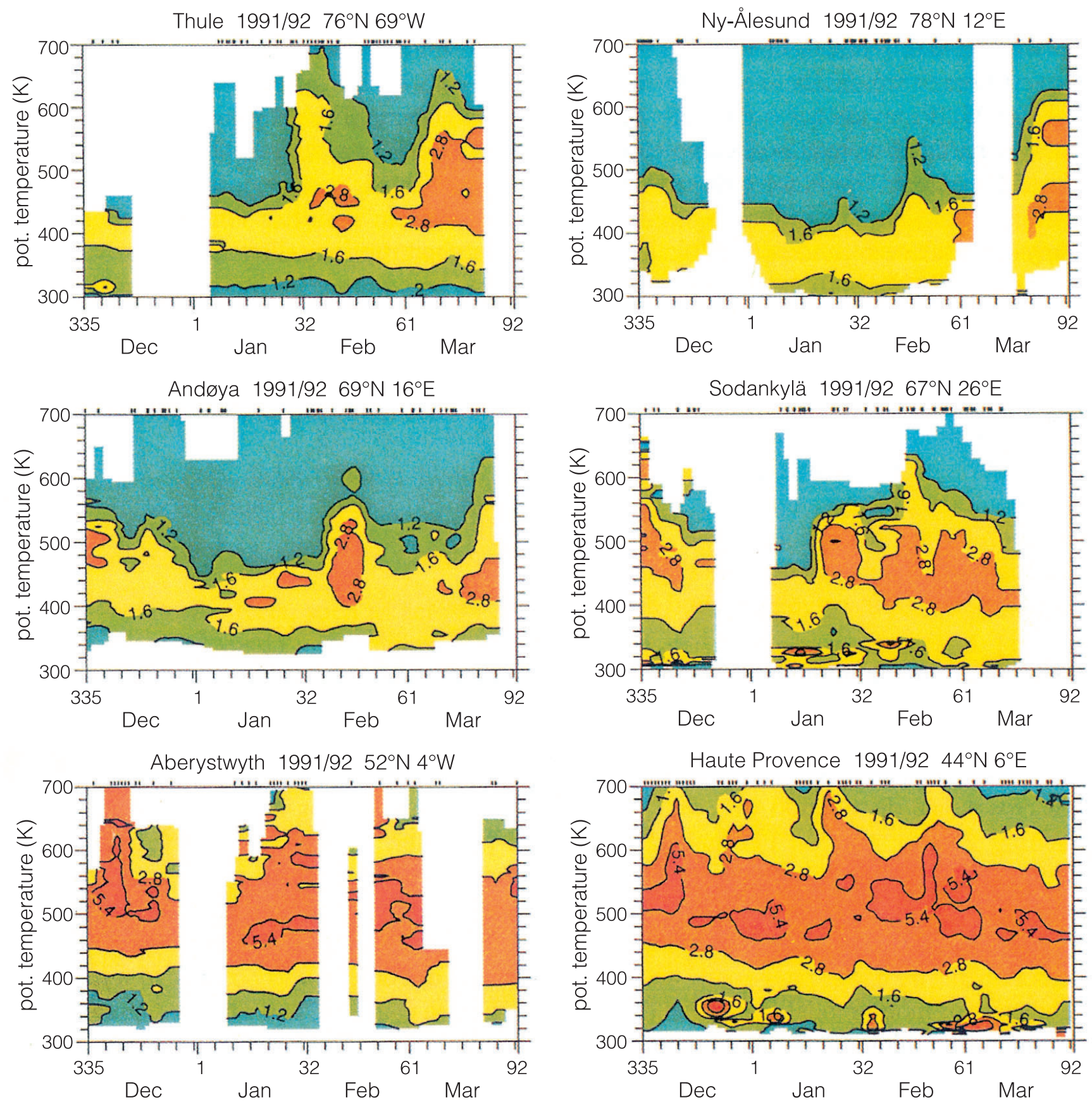

Fig. 7. Temporal development of the backscatter ratios at six lidar stations in the period December 1991 through March 1992 during EASOE (European Arctic Stratospheric Ozone Experiment). The bars above the plots indicate times of the measurements. Isolines are set to values of 1.2, 1.6, 2.8, and 5.4 in order to reveal greater details for the lower values. Adapted from Neuber et al. (1994) (copyright by the American Geophysical Union).

to 23, 1992 Thule was inside the polar vortex. The profiles from this period are rather similar (cf. fig. 8a) with increasing particle loading from the tropopause up to about $17 \mathrm{~km}$, where a sharp cut-off occurs, and with clear layered structures between 13 and $17 \mathrm{~km}$, where the backscattering is strongly enhanced, compared to pre-volcanic levels. Layering can also be seen in the ozone profiles in the same altitude range, and are probably caused by horizontal transport 
of particles and ozone of different origin into the layers. Above $18 \mathrm{~km}$ (above the upper particle layers) the ozone profiles are more smooth. In the period of the last two flights (February, 2 and 5) Thule was outside the vortex; the profiles ( $c f$. fig. $8 b)$ show large enhancements in the backscatter ratios, and also increased values of the ozone concentrations. Temperatures (not shown) were too high for PSC formation at Thule throughout the winter.
Aerosol profiles in the winter north polar vortex were also measured at Thule and Alert with balloon-borne backscatter sondes in the winter 1992-1993 (Rosen et al., 1994). Stratospheric temperatures were sufficiently low to expect the formation of PSCs, but the positive identification of typical PSCs was made difficult by the presence of considerable volcanic aerosol background. An unusual scattering layer that can probably be identified as some type of PSC

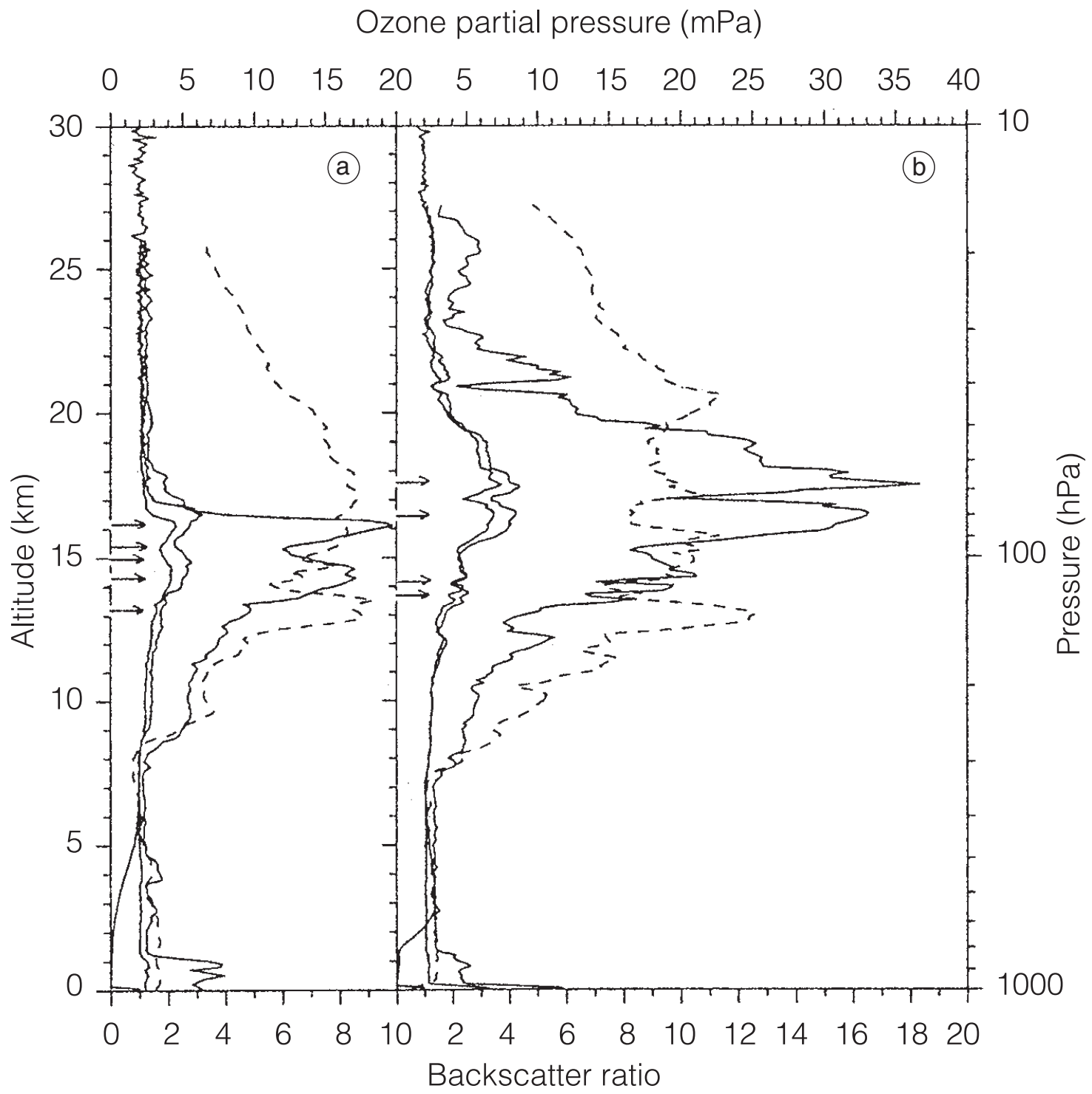

Fig. 8a,b. a) Vertical profiles of aerosol backscatter ratio in three wavelengths (solid lines) and ozone partial pressure (dashed) from 23 January 1992, when Thule was inside the polar vortex. b) Observations on 5 February, when Thule was outside the polar vortex. The lidar backscatter profile is intermediate between the $940 \mathrm{~nm}$ (large values) and $480 \mathrm{~nm}$ sonde profiles. The arrows indicate layers where parameters of size distributions have been derived. The tropopause is located at $8 \mathrm{~km}$ where the ozone pressure increases sharply. The pressure scale is approximate (Larsen et al., 1994b). 
was not associated with as much backscatter as observed in previous non-volcanic years with similar stratospheric temperatures. The Arctic volcanic aerosol layer was found to produce a small but significant depolarized backscattered signal. This preliminary result could be interpreted as indicating the presence of some nonspherical particles containing inclusions of irregular shapes with differing refractive index.

An investigation of the influence of synoptic temperature histories on the physical properties of PSC particles was carried out by Larsen et al. (1997). A large set of PSC observations, obtained throughout four winters between 1989 and 1996 by balloon-borne backscatter sondes from seven locations in the Arctic at low stratospheric temperatures, were analyzed by means of isentropic airparcel trajectories, providing the synoptic temperatures of the observed particles. It appeared from the observations that liquid type 1b PSC particles can be cooled to very low temperatures, approaching the ice frost point, without causing them to freeze. Most of the liquid type $1 \mathrm{~b}$ particles were observed in the process of an ongoing, relatively fast, and continuous cooling from temperatures clearly above the NAT condensation temperature. The particles are mostly seen at the edge of a cloud shortly after they enter the cold area. On the other hand, it appears that a relatively long period, with a duration of at least 1-2 days, at temperatures below $T_{\mathrm{NAT}}$, provides the conditions which may lead to the production of solid type 1a PSCs. Solid PSC particles are therefore expected to be observed in aged clouds. Figure 9 shows a histogram of the time that PSC particles have spent at temperatures below $T_{\mathrm{NAT}}$ before being observed. It is seen that most of the type 1a PSCs have existed at temperatures below $T_{\mathrm{NAT}}$ for more than 1-2 days, while the type $1 b$ PSCs typically have spent less than $24 \mathrm{~h}$ at low temperatures.

\section{Conclusions/outstanding issues}

The problem of quantifying heterogeneous processing rates in the stratosphere is compounded by the problem of identifying the various particle types that are likely to be present. So, much of the effort in PSC research has been

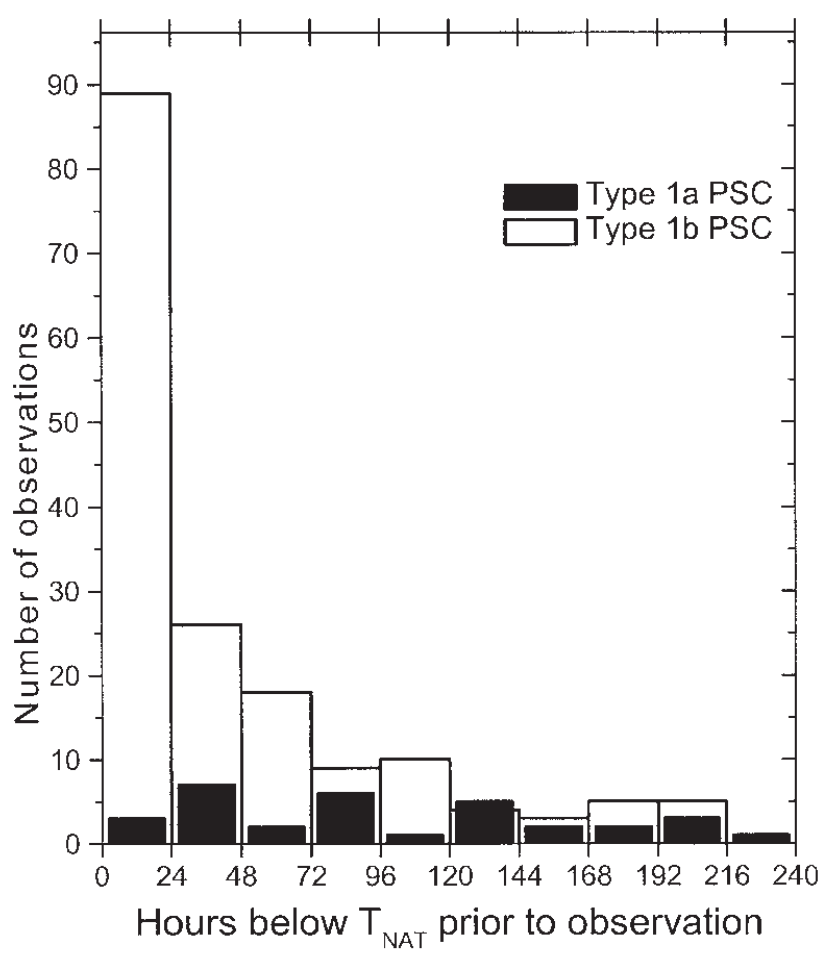

Fig. 9. Histogram showing the time that solid type 1a (filled bars) and liquid type 1b PSC particles (open bars) have spent at temperatures below $T_{\mathrm{NAT}}$ before being observed.

directed towards understanding the processes that control PSC type; thus, directly addressing the question of why PSCs are sometimes liquid and sometimes solid. There are two reasons for wanting to know the answer to this question, which are:

1) The composition and phase of the PSC particles determines the rate of heterogeneous reactions, which in turn influences the abundance of active chlorine and hence the ozone loss rate.

2) The phase of the PSCs controls the process of denitrification, which occurs only when a few particles solidify as nitric acid hydrates and grow large enough to sediment.

The significance of denitrification for ozone depletion in the Arctic has been demonstrated by Waibel et al. (1999), who were able to reproduce the observed denitrification in the winter 19941995. Investigations show that the Arctic denitrification is highly sensitive to temperature changes. Thus a reduction of the Arctic vortex temperature by 5 degrees, predicted to occur in 
a doubled $\mathrm{CO}_{2}$ climate, leads to removal of more than $80 \%$ of the available $\mathrm{NO}_{\mathrm{y}}$. The simulations show that reducing the inorganic chlorine concentration to prescribed year-2070-conditions (comparable to 1980) will result in nearly the same ozone depletion as in the winter1994-1995, indicating that enhanced denitrification will delay the recovery of the Arctic ozone layer until late in the century. Better understanding regarding composition and formation of type 1a PSCs is needed, because solid particles play a significant role in denitrification.

Increasing greenhouse-gas concentrations are expected to result in a more stable Arctic polar vortex with colder temperatures in the lower stratosphere and increased ozone depletion (Shindell et al., 1998), and despite the limits on CFC production uncertainties remain about the exact timing of recovery of the ozone layer. The results of Shindell et al. (1998) suggest that the maximum depletion of polar ozone may occur roughly 15 years after the decline in the emission of CFCs. Thus recovery of the Earth's ozone layer may take place later than currently expected. A significant cooling of the Arctic lower stratosphere in March has occurred over the last two decades. Pawson and Naujokat (1999) showed that in late winter there has been an increase in the area of temperatures cold enough to form PSCs and hence produce conditions where significant ozone loss can occur.

Investigations of the future background levels of stratospheric aerosols are essential for assessments of trends and anthropogenic effects on the stratospheric aerosol layer. An anthropogenic source of aerosols may be sulphur emissions in the form of $\mathrm{SO}_{2}$ or sulphate particles from increasing aircraft traffic.

\section{Acknowledgements}

I thank Niels Larsen for helpful discussions and comments.

\section{REFERENCES}

BRIFFA, K.R., P.D. JONES, F.H. SCHWEINGRUBER and T.J. OSBORN (1998): Influence of volcanic eruptions on Northern Hemisphere summer temperature over the past 600 years, Nature, 393, 450-454.

Carslaw, K.S., B.P. Luo, S.L. Clegg, T. Peter, P. BRIMBLECOMBE and P.J. CRUTZEN (1994): Stratospheric aerosol growth and $\mathrm{HNO}_{3}$ gas phase depletion from coupled $\mathrm{HNO}_{3}$ andwater uptake by liquid particles, Geophys. Res. Lett., 21, 2479-2482.

Carslaw, K.S., M. Wirth, A. Tsias, B.P. Luo, A. DÖRNBRACK, M. LEUTBECHER, H. VOLKERT, W. RENGER, J.T. BACMEISTER and T. PETER (1998): Particle microphysics and chemistry in remotely observed mountain polar stratospheric clouds, J. Geophys. Res., 103, 5785-5796.

CHAPMAN, S. (1932): Clouds high in the stratosphere, Nature, 129, 497-499.

Chazette, P., C. David, J. Lefrere, S. Godin and G. MEgIE (1995): Comparative lidar study of the optical, geometrical and dynamical properties of stratospheric post-volcanic aerosols following the eruptions of El Chicon and Mount Pinatubo, J. Geophys. Res., 100, 23,195-23,207.

Di Girolamo, P., M. Cacciani, A. Di Sarra, G. Fiocco and D. FUÀ (1994): Lidar observations of the Pinatubo aerosol layer at Thule, Geophys. Res. Lett, 21, 12951298.

Di Sarra, A., M. Cacciani, P. Di Girolamo, G. Fiocco, D. FUA, B. KNUDSEN, N. LARSEN and T.S. JøRGENSEN (1992): Observations of correlated behavior of stratospheric ozone and aerosol at Thule during winter 1991-1992, Geophys. Res. Lett, 19, 1823-1826.

di Sarra, A., M. Cacciani, G. Fiocco, D. Fua, T.S. JØRGENSEN, B. KNUDSEN, N. LARSEN and I.S. MIKKELSEN (1995): Ozone and aerosol correlated observations at Thule, Greenland, in the period 19911994, J. Geophys. Res., 100, 25,965-25,977.

EATHER, R.H. (1980): Majestic Lights: The Aurora in Science, History, and the Arts, Am. Geophys. Union, Washington DC, pp. 324.

FARMAN, J.C., B.G. GARDINER and J.D. SHANKLIN (1985): Large losses of total ozone in Antarctica reveal seasonal $\mathrm{ClO}_{\mathrm{x}} / \mathrm{NO}_{\mathrm{x}}$ interaction, Nature, 315, 207-210.

FIOCCO, G. and G. GRAMS (1964): Observation of aerosol layer of $20 \mathrm{~km}$ by optical radar, J. Atmos.. Sci., 21, 323-324.

GRAMS, G. and G. FIOCCO (1967): Stratospheric aerosol layer during 1964 and 1965, J. Geophys. Res. 72, 3523-3542.

Hitchman, M.H., M. MCKAY and C.R. TREPTE (1994): A climatology of stratospheric aerosol, J. Geophys. Res., 99, 20,689-20,700.

JÄGER, H., V. FREUdENTHALER and F. HOMSBURG (1995): Aerosol lidar observations at Garmisch-Partenkirchen during SESAME, in Polar Stratospheric Ozone 1995, edited by J.A. PYLE, N.R.P. HARRIS and G.T. AMANATIDIS, Air Pollution Research Report 56, European Commission, 154-157.

LARSEN, N., B. KNUDSEN, I.S. MiKKELSEN, T.S. JøRGENSEN and P. ERIKSEN (1994a): Ozone depletion in the Arctic stratosphere in early 1993, Geophys. Res. Lett., 21, 1611-1614.

Larsen, N., B. Knudsen, T.S. Jørgensen, A. di SARra, D. FuÀ, P. Di Girolamo, G. Fiocco, M. Cacciani, J.M. Rosen and N.T. KJOME (1994b): Backscatter 
measurements of stratospheric aerosols at Thule during January-February 1992, Geophys. Res. Lett, 21, 13031306.

LARSEN, N., B.M. KNUdSEN, J.M. Rosen, N.T. KJOME, R. NEUBER and E. KYRÖ (1997): Temperature histories in liquid and solid polar stratospheric cloud formation, $J$. Geophys. Res., 102, 23,505-23,517.

LARSEN, N., I.S. MIKKELSEN, B.M. KNUDSEN, J. SCHREINER, C. Voigt, K. MAUersberger, J.M. Rosen and N.T. KJOME (2000): Comparison of chemical and optical in-situ measurements of polar stratospheric clouds, $J$. Geophys. Res., 105, 1491-1502.

Manney, G.L., L. Froidevaux, J.W. Waters, R.W. ZureK, W.G. READ, L.S. Elson, J.B. Kumer, J.L. Mergenthaler, A.E. Roche, A. O’Neill, R.S. HARWOOD, I. MACKENZIE and R. SWINBANK (1994): Chemical depletion of ozone in the Arctic lower stratosphere during winter 1992-93, Nature, 370, 429-434.

Neuber, R., G. Beyerle, G. Fiocco, A. Di SARra, K.H. Fricke, C.H. DAVID, S. Godin, B.M. KNUdSEN, L. StefanutTi, G. VAughan and J.-P. Wolf (1994): Latitudinal distribution of stratospheric aerosols during the EASOE winter 1991-92, Geophys. Res. Lett., 21, 1283-1286.

PAWSON, S. and B. NAUJOKAT (1999): The cold winters of the middle 1990s in the northern lower stratosphere, $J$. Geophys. Res., 104, 14,209-14,222.

REID, S.J. and G. VAUGHAN (1991): Lamination in ozone profiles in the lower stratosphere, $Q . J$. R. Meteorol. Soc., 117, 825-844.

Rosen, J.M. and N.T. KJOME (1991): Backscattersonde: a new instrument for atmospheric aerosol research, Appl. Opt., 30, 1552-1561.

Rosen, J.M., N.T. KJOME, H. FAST and N. LARSEN (1994): Volcanic aerosol and polar stratospheric clouds in the winter 1992-1993 north polar vortex, Geophys. Res. Lett., 21, 61-64.

Schreiner, J., C. Voigt, A. Kohlmann, F. Arnold, K. MAUERSBERGER and N. LARSEN (1999): Chemical analysis of polar stratospheric cloud particles, Science, 283, 968-970.

ShINDELL, D.T., J.M. REEVES, L.K. EMMONS and R.L. DE
ZAFRA (1994): Arctic chlorine monoxide observations during spring 1993 over Thule, Greenland and implications for ozone depletion, J. Geophys. Res., 99, 25,697-25,704.

SHINDELL, D.T., D. RiND and P. LONERGAN (1998): Increased polar stratospheric ozone losses and delayed eventual recovery owing to increasing greenhouse-gas concentrations, Nature, 392, 589-592.

SOlOMON, S., R.R, GARCIA, F.S. Rowland and D.J. WUEBBLES (1986): On the depletion of Antarctic ozone, Nature, 321, 755-758.

STANFORD, J.L. and J.S. DAVIS (1974): A century of stratospheric cloud reports: 1870-1972, Bull. Am. Meteorol. Soc., 55, 213-219.

STøRMER, C. (1929): Remarkable clouds at high altitudes, Nature, 123, 260-261.

TABAZADEH, A., R.P. TURCO, K. DRDLA and M.Z. JACOBSON (1994): A study of Type 1 polar stratospheric cloud formation, Geophys. Res. Lett., 21, 1619-1622.

Trepte, C.R., R.E. VEIGA and M.P. MCCORMICK (1993): The poleward dispersion of Mount Pinatubo volcanic aerosol, J. Geophys. Res. 98, 18,563-18,573.

TurCo, R.P., R.C. WhitTen and O.B. ToON (1982): Stratospheric aerosol: observation and theory, Rev. Geophys. Space Phys., 20, 233-279.

VOIGT, C., J. SCHREINER, A. KOHLMANN, K. MAUERBERGER, N. Larsen, T. Deshler, C. Kröger, J. Rosen, A. ADRIANI, G. Di DONFRANCESCO, F. CAIRO, J. OVARLEZ, H. Ovarlez, C. DAVID and A. DÖRNBRACK (2000): Nitric Acid Trihydrate (NAT) in polar stratospheric cloud particles, Science, 290, 1756-1758.

Waibel, A.E., Th. Peter, K.S. Carslaw, H. Oelhaf, G. Wetzel, P.J. Crutzen, U. Pöschl, A. Tsias, E. REIMER and H. FISHER (1999): Arctic ozone loss due to denitrification, Science, 283, 2064-2069.

WEISS, P.S., J.E. JOHNSON, R.H. GAMMON and T.S. BATES (1995): Reevaluation of the open ocean source of carbonyl sulfide to the atmosphere, J. Geophys. Res., 100, 23,083-23,092.

WORLD METEOROLOGICAL ORGANIZATION (WMO) (1999): Scientific Assessment of Ozone Depletion: 1998, Rep. 44, Global Ozone Research and Monitoring Project, Geneva, Switzerland. 